\title{
OS “REMANESCENTES DAS COMUNIDADES DE QUILOMBOS": RESSEMANTIZAÇÃO E ESVAZIAMENTO JURÍDICO DA CATEGORIA
}

\section{THE “REMNANTS OF QUILOMBOS COMMUNITIES": RESEMANTIZATION AND JURIDICAL EMPTYING OF THE CATEGORY}

\author{
Rosangela Lima Brasil ${ }^{1}$ \\ $10.21665 / 2318-3888 . v 5 n 10 p 262-281$
}

\section{RESUMO}

O artigo 68 do Ato das Disposições Constitucionais Transitórias da Constituição Federal de 1988, que garante o direito de titulação das terras ocupadas pelos remanescentes das comunidades de quilombos, insere-se no contexto de reconhecimento por parte do Estado brasileiro da pluralidade cultural e étnica que conforma sua população. A efetivação deste direito somente se tornou possível a partir da definição desse novo sujeito, o remanescente de quilombos. A objetivação dessa categoria jurídica, manifesta em textos legais, tornou-se a base de fundamentação dos princípios de regulamentação das políticas públicas voltadas a essa parcela específica da população. No entanto, notase a forte influência exercida por estudos promovidos em outras áreas do conhecimento, como a Antropologia, a Sociologia, a História e a Geografia, nessas conceituações promovidas pelo Estado brasileiro, que passa a adotar termos como território, identidade étnica e comunidade em seus dispositivos legais. Este artigo tem como objetivo discutir a ressemantização da categoria jurídica "remanescente de quilombos", promovida por profissionais de diversas áreas, em especial por juristas e antropólogos, e sua apropriação e mobilização em dispositivos jurídicos de classificação e regulamentação, visando refletir sobre os processos de reconhecimento e valorização da diversidade cultural e da pluralidade étnica promovidos pelo Estado brasileiro e a lógica que os subjaz. Para tanto, serão abordados alguns escritos elaborados por estudiosos que se dedicaram a debater a definição desse novo sujeito de direito, apontando a multiplicidade de situações por ele abarcadas. Em seguida, szerão analisadas algumas passagens do Programa Brasil Quilombola (2004), apresentado pelo governo federal para nortear as políticas voltadas às "comunidades remanescentes de quilombos" do Brasil, à luz crítica de autores que discutem os limites de atuação do Estado moderno no campo da pluralidade.

Palavras-chave: Ressemantização. Comunidades Remanescentes de Quilombos. Direitos Étnicos. Pluralidade.

\footnotetext{
${ }^{1}$ Bacharel em Antropologia pela Universidade Estadual de Campinas (2008), mestranda em Ciências Sociais pela Universidade Federal do Maranhão (2016- ), atua na equipe de Regularização de Territórios Quilombolas da Superintendência Regional do Incra no Maranhão desde 2013, como analista em antropologia. E-mail: lima_rosas@yahoo.com.br.
} 


\begin{abstract}
Article 68 of the Act of Transitional Constitutional Provisions of the Federal Constitution of 1988, which guarantees the right to title the lands occupied by the remnants of quilombo communities, is part of the recognition by the Brazilian State of the cultural and ethnic plurality that conforms Population. The realization of this right only became possible from the definition of this new subject, the remnants of quilombos. The objectification of this legal category, manifested in legal texts, became the basis for the principles of regulation of public policies aimed at this specific portion of the population. However, the strong influence exerted by studies promoted in other areas of knowledge, such as anthropology, sociology, history and geography, can be seen in these conceptualizations promoted by the Brazilian State, which adopts terms such as territory, ethnic identity and Community in their legal devices. This article aims to discuss the resemantization of the legal category "remnants of quilombos", promoted by professionals from different areas, especially by jurists and anthropologists, and their appropriation and mobilization in legal classification and regulation devices, aiming to reflect on the processes of recognition and appreciation of the cultural diversity and ethnic plurality promoted by the Brazilian State and the logic that underlies them. To do so, will be approached some writings elaborated by scholars who were dedicated to discuss the definition of this new subject of law, pointing out the multiplicity of situations covered by it. Next, some passages of the Brasil Quilombola Program (2004) presented by the federal government will be analyzed to guide the policies aimed at the "remaining communities of quilombos" in Brazil, in the critical light of authors who discuss the limits of the modern state in the field of plurality.
\end{abstract}

Keywords: Resemantization. Remaining Communities of Quilombos. Ethnic Dights. Plurality. 


\section{Introdução}

O reconhecimento pelo Estado brasileiro do direito aos "remanescentes das comunidades de quilombos" de terem as terras que ocupam tituladas em seu nome, cabendo ao próprio Estado realizar as ações necessárias a este fim, inseriu um novo sujeito de direito em nosso campo jurídico, ainda pouco conhecido e carente da definiçãa necessária à construção e direcionamento dos procedimentos de cunho jurídico-administrativo, que tornassem possível o cumprimento do novo artigo 2 presente no Ato das Disposições Constitucionais Transitórias da Constituição Federal de 1988.

Uma série de debates foram travados, sendo protagonizados principalmente por juristas, antropólogos, movimentos sociais e pelos próprios grupos que poderiam ser abarcados pela nova categoria, objetivando a construção conceitual desse novo sujeito. Vigorava até então um quadro de referência bastante limitado acerca da concepção de quilombos, presente no imaginário da sociedade brasileira mais ampla, o qual compreendia ideias em torno de grupos numericamente reduzidos, socialmente isolados, compostos a partir de uma única matriz racial ${ }^{3}$, tecnologicamente atrasados, com forte coesão social (principalmente devido ao princípio da endogamia), cujas origens remontariam ao período escravocrata.

Esses debates apontaram o quanto as limitações impostas por essa concepção de quilombo, - acrescida da forte conotação negativa cunhada sobre o termo desde sua gênese ${ }^{4}$, que a caracterizava enquanto formação criminosa, como caso policial poderiam comprometer a aplicabilidade do termo às situações concretas existentes em quase toda extensão do território brasileiro. Numerosas, essas comunidades negras congregavam inúmeras diferenças entre si e apresentavam características que fugiam da

\footnotetext{
2 Artigo 68 do Ato das Disposições Constitucionais Transitórias da Constituição Federal Brasileira de 1988, que estabelece: "Aos remanescentes das comunidades dos quilombos que estejam ocupando suas terras é reconhecida a propriedade definitiva, devendo o Estado emitir-lhes os títulos respectivos" (BRASIL, 1988).

${ }^{3}$ Utilizo aqui a ideia de matriz racial por estar me referindo a concepções populares que, alheias aos debates antropológicos acadêmicos, operam normalmente através de classificações vinculadas diretamente a características fenotípicas que, no Brasil, servem para enquadrar os sujeitos em brancos, negros ou indígenas.

4 Definição de quilombo pelo Conselho Ultramarino em 1740: "Toda habitação de negros fugidos, que passem de cinco, em parte despovoada, ainda que não tenham ranchos levantados nem se achem pilões nele" (Cons. Ultramarino, 1740, apud Chagas, 2001:216).
} 
concepção popularizada acerca dos quilombos no Brasil. A inadequação entre imaginário popular e as distintas configurações assumidas por essas "comunidades" conduzidas por diferentes processos históricos, impôs a esses estudiosos a tarefa de ressemantizar o termo "quilombos" 5 .

Promoveu-se a inversão do termo "remanescente das comunidades de quilombos", tal qual cunhado na Constituição, por "comunidades remanescentes de quilombos", alteração que enfatiza o caráter coletivo desse tipo de formação social e dos direitos a ele vinculados, retirando o aspecto residual ao informar que, embora tenham suas origens nos diversos processos de organização e socialização desencadeados durante e após o período escravista, estando historicamente vinculados a ele, esses grupos não necessariamente apresentam-se como continuidades dos antigos quilombos, congregando muitas vezes características que chegam a contradizer aquelas presentes no imaginário popular, sendo o quilombo urbano, talvez, o melhor exemplo de desencaixe.

Alguns autores (como ARRUTI, 1997; CHAGAS, 2001) atentaram para o caráter político, contextual e construtivo da nova categoria, o seu poder de conferir direitos a partir de uma prática classificatória e restritiva do Estado, apontando a necessidade de se compreender a categoria remanescentes de quilombos como construção externa, inserida num campo de disputa política e identitária que envolve agentes detentores de parcelas diferenciadas de poder de definição e condução das novas ações a serem construídas em torno do artigo 68 do ADCT. Ao mesmo tempo, esses autores são enfáticos em apontar a organização e representação internas aos grupos sociais desses pretensos (ou não) quilombolas, suas diferentes e particulares formas de se relacionar com o espaço geográfico ocupado e, em especial, o vínculo histórico com ele estabelecido, como elementos fundamentais de sua identidade étnica.

${ }^{5}$ Entre 17 e 18 de outubro de 1994, o Grupo de Trabalho sobre Comunidades Negras Rurais, elabora o Documento que traz uma proposta de ressemantização do termo quilombo. Assinam o documento Ilka Boaventura Leite, Neusa Gusmão, Lúcia Andrade, Dimas Salustiano da Silva, Eliane Cantarino O’Dwyer e João Pacheco de Oliveira. (ARRUTI, 2008) 
Os conceitos e categorias debatidos (e em constante construção), principalmente no campo da Antropologia, passaram a ser acionados pelo Estado brasileiro em diferentes dispositivos jurídicos relativos às políticas de reconhecimento identitário e promoção de ações voltadas à correção de problemas sociais atuais cujas origens remontam à escravidão e a um processo não tutelado de inserção do negro na sociedade brasileira. A regularização das terras ocupadas pelos "remanescentes das comunidades de quilombos" passa a constituir uma dessas ações, sendo subordinado, assim, aos processos de reconhecimento identitário instituídos pelo Estado brasileiro.

Embora incorporando terminologias, apresentando propostas de políticas baseadas em processos de autodefinição identitária e procurando resguardar o direito de representação dos grupos que seriam assistidos por tais políticas, o deslocamento de conceitos e categorias complexos do campo acadêmico para o campo jurídico foi acompanhado de inúmeras alterações calcadas em diferentes referenciais epistemológicos, que marcam as diferentes concepções acerca da aplicabilidade (e da própria pertinência de uma política estatal de reconhecimento identitário nos moldes adotados pelo Brasil) da categoria remanescente de quilombos e de sua operacionalização pelo Estado, por seus possíveis beneficiários e pelos inúmeros, distintos e concorrentes mediadores que atuam nesses processos.

Nesse processo de apropriação de conhecimentos, a figura do antropólogo ${ }^{6}$ ganha proeminência, passando a desempenhar o papel de mediador e tradutor das relações e ações estabelecidas entre as autodefinidas comunidades remanescentes de quilombos e as agências governamentais responsáveis pela implantação das políticas de Estado destinadas a essa parcela da população, articuladas através do Programa Brasil Quilombola (2004).

\footnotetext{
${ }^{6} \mathrm{~A}$ centralidade dada ao antropólogo nos processos de identificação territorial, diretamente vinculados a questões de ordem religiosa, produtiva, cosmológica, reafirma o lugar ocupado pela antropologia no campo de produção de conhecimentos científicos. De acordo com Souza Lima (2012, p. 204), o estudo de minorias consiste no foco da antropologia: "A compreensão de como esses grupos ou coletividades se organizam, vivenciam suas fronteiras sociais em face de outras coletividades e processam transformações de diversas ordens é matéria cara à investigação antropológica, sobretudo em universos complexos como os das sociedades contemporâneas, em que os indivíduos podem ser classificados com base em diversas ordens de pertencimento social".
} 
Ao longo de quatro anos de trabalho no Serviço de Regularização de Territórios Quilombolas na Superintendência Regional do Incra do Maranhão, tenho observado nos discursos de diversos grupos sociais, instituições governamentais e entidades com que estabelecemos contato no decorrer das diferentes etapas por que passam os processos de regularização, a pluralidade semântica das categorias mobilizadas na reivindicação do reconhecimento institucional do direito territorial de grupos potencialmente abarcados pela categoria remanescente de quilombos, pluralidade frequentemente confrontada com as limitações impostas pelas definições apresentadas em textos legais. É nesse excedente semântico que encontramos uma gama de identidades não reconhecidas, de experiências históricas e culturais não valorizadas.

Este artigo tem como objetivo refletir acerca do processo de apropriação de debates promovidos por estudiosos da temática quilombola em dispositivos jurídicos de classificação e regulamentação, visando problematizar os processos de reconhecimento e valorização da diversidade cultural e pluralidade étnica promovidos pelo Estado brasileiro e a lógica que os subjaz.

Para tanto, serão discutidos alguns escritos de estudiosos que se envolveram nos debates que promoveram a ressemantização do termo "remanescente de quilombos". Alguns pontos do Programa Brasil Quilombola (2004) serão destacados a fim de exemplificar o deslocamento de conceitos e noções presentes nesses debates, de cunho fortemente antropológico, em textos de caráter jurídico-normativo, buscando - à luz de discussões que têm como foco refletir acerca das limitações do Estado nacional moderno em atuar numa perspectiva efetivamente multicultural e pluriétnica - atentar aos perigos inerentes à busca de objetivação de questões delicadas relacionadas à representação e ao reconhecimento identitário atrelados a políticas públicas governamentais de garantias de direitos territoriais, históricos e culturais.

Por fim, apresentarei minhas considerações finais, relacionando as discussões desenvolvidas ao longo do texto com alguns entraves ${ }^{7}$ que dificultam a execução da

7 É importante ressaltar que, embora o foco deste artigo seja efetuar uma análise da apropriação e deslocamento do campo antropológico para o jurídico-normativo de noções presentes nas propostas de ressemantização do conceito "remanescentes de quilombos", não desconsidero a ação de outros inúmeros 
política de regularização de territórios quilombolas pelo Serviço de Regularização de Territórios Quilombolas na Superintendência Regional do Incra no Maranhão, decorrentes de processos classificatórios homogeneizantes que colaboram com a promoção de novas invisibilidades.

\section{A ressemantização do termo quilombo: propostas de aberturas semânticas}

Chagas (2001) discute a base do direito garantido pelo artigo 68 do ADCT sob a prerrogativa do reconhecimento de especificidades socioculturais e históricas. A autora atenta ao caráter generalizante das categorias adotadas em textos jurídico-normativos e pondera que "o desafio que se apresenta à prática antropológica fundamenta-se em produzir uma problematização das próprias categorias jurídicas que foram concebidas com um caráter genérico" (CHAGAS, 2001, p.211).

O centro dessa análise crítica, para a autora, seria a própria categoria "remanescente de quilombos", que muitas vezes é marcada pela construção de um estereótipo calcado em noções pré-concebidas e sem aplicabilidade em casos concretos.

\footnotetext{
Mesmo se tratando de um novo cenário de reconhecimento, certas demandas de caracterização dessas comunidades são feitas ou traduzidas com base em estereótipos ou enquadramentos que pouco ou nada correspondem a suas realidades. Nessa direção, faz sentido supor que, muito embora a expressão "remanescentes das comunidades dos quilombos" tenha sido cunhada como categoria jurídica geradora de direitos, esse reconhecimento não suprime a possibilidade de problematizá-la no quadro das dificuldades decorrentes do próprio processo de sua interpretação (CHAGAS, 2001, p. 215).
}

Para a autora, caberia aos laudos antropológicos a função de construir diagnósticos das situações sociais investigadas, oferecendo suporte às ações governamentais de aplicação dos direitos constitucionais, evidenciando as diferentes formas de usar e ocupar a terra,

fatores que interferem nos encaminhamentos e na dinâmica de tramitação dos processos. Problemas relacionados à desestruturação física e financeira do Incra; falta de empenho político na estruturação e ampliação da política; o excesso de trâmites burocráticos que marcam os processos da administração pública brasileira; as relações de poder que se estabelecem nos campos econômico, político e social e que perpassam a política de forma transversal, são alguns dos fatores que agem no constante delinear que cada caso específico toma. 
relacionadas às distintas configurações sócio-históricas desses grupos e à diversidade de formas de produção de distintividades.

A explicitação da existência dessas diversas formas de produção de distintividades fornece outros conteúdos aos conceitos de resistência e autonomia. De fato, seria inconcebível, do ponto de vista da criatividade social, supor que os diferentes grupos tenham oferecido uma única resposta, um único modelo de resistência frente à sociedade escravocrata (CHAGAS, 2001, p.217).

João José Reis (1995-1996), ao estudar os processos de formação dos quilombos no período escravista, aponta a diversidade de configurações assumidas por essas organizações sociais, em decorrência do hibridismo cultural e das alianças sociais travadas como estratégias fundamentais de sobrevivência.

Essa disponibilidade para mesclar culturas era um imperativo de sobrevivência, exercício de sabedoria também refletida na habilidade demonstrada pelos quilombolas de compor alianças sociais, as quais inevitavelmente se traduziam em transformações e interpenetrações culturais (REIS, 1995-1996, p.20).

Indo mais a fundo, o autor remonta à origem da diversidade de experiências da população negra no Brasil, à experiência anterior à escravidão, bem como aos diferentes contornos assumidos pela ordem escravista:

Os africanos para aqui trazidos como escravos não eram tábula rasa sobre a qual foi simplesmente inscrita a nova experiência como escravos. A própria experiência escrava não foi a mesma em todo lugar e todas as épocas, apesar de a escravidão estar em todo lugar e ter durado mais de três séculos (REIS, 1995-1996, p. 23).

$\mathrm{Na}$ discussão acerca dos impactos de implantação de políticas de reconhecimento identitário a partir da construção de categorias jurídicas, Arruti (1997) atenta para a dimensão constitutiva desses processos legais, elemento que deve ser considerado na abordagem das políticas relacionadas a esses segmentos, bem como na própria reflexão crítica acerca desses processos de reconhecimento, representação e assunção identitários.

Talvez tenha alguma utilidade lembrar que o trabalho genealógico, neste caso, é apenas o ponto de partida de uma crítica à ideia de que tais denominações são simples institucionalizações de divisões espontâneas do mundo social, ou, de outra forma, "batismos" de "seres naturais". A história dos nomes é também a história dos seres e instituições que eles nomeiam, do seu surgimento, desaparecimento e mutação (ARRUTI, 1997, p. 22-23). 
Voltando-se à questão do poder homogeneizante de categorias identitárias externamente construídas, capazes de abarcar um amplo leque de configurações sociais, o autor atenta aos processos de identificação e construção de alianças entre grupos muito distintos e à possibilidade de acirramento das fronteiras entre grupos social, identitária e historicamente próximos. Tais transformações seriam consequências de uma

[...] paradoxal composição entre tendências globais e paroquiais, frente à qual o Estado e a política nacional assumem posturas ambíguas. Os novos direitos (indígenas nas décadas de 60 e 70 e negros nos anos 90) têm por efeito produzir uma confusão ou sobreposição entre identidade e terra que leva ao desequilíbrio do regime de relações estabelecido ao longo de uma secular história de convivência (ARRUTI, 2000, p.121).

Como demonstrado a partir das proposições dos autores por ora apresentados, as discussões acerca da nova categoria jurídica "remanescente de quilombos" suscitaram um tipo de debate crítico que apontava a necessidade de se proceder a uma análise genealógica acerca da própria categoria em debate. Como resultado, temos estudos que apontam a grande diversidade de situações que podem ser abarcadas pela nova categoria, apontamentos acerca dos perigos à consolidação dos direitos territoriais e culturais garantidos pela Constituição Federal de 1988 em vista da construção de modelos essencialistas e cristalizados acerca do "remanescente de quilombos" indicam o caráter político da representação identitária e seu poder de transformação social e, sobretudo, o impacto que as classificações oficiais promovidas pelo Estado exercem sobre a realidade social dos grupos por elas enquadrados.

\section{Programa Brasil Quilombola: cristalização e homogeneização com base no respeito às diferenças}

Embora muitos debates e estudos tenham sido promovidos ao longo da década de 1990 em torno da definição do sujeito de direito do artigo 68, somente em 2003, com a promulgação do Decreto no 4.887 que "Regulamenta o procedimento para identificação, reconhecimento, delimitação, demarcação e titulação das terras ocupadas por remanescentes das comunidades dos quilombos de que trata o art. 68 do Ato das Disposições Constitucionais Transitórias", esse sujeito é definido juridicamente enquanto 
[...] grupos étnico-raciais, segundo critérios de auto-atribuição, com trajetória histórica própria, dotados de relações territoriais específicas, com presunção de ancestralidade negra relacionada com a resistência à opressão histórica sofrida (BRASIL, 2004).

É a partir dessa definição, e atribuindo ao grupo a concepção de unidade social coesa, que é concebido o Programa Brasil Quilombola (PBQ), elaborado pelo Governo Federal no ano de 2004, com coordenação da Secretaria Especial de Políticas de Promoção da Igualdade Racial, tendo como objetivo a promoção de ações

[...] que visam alterar, de forma positiva, as condições de vida e de organização das comunidades remanescentes de quilombo, promovendo o acesso ao conjunto de bens e serviços sociais necessários ao seu desenvolvimento, considerando sempre a realidade sociocultural destas comunidades (BRASIL, 2004, p. 5).

Em torno desse objetivo, o Programa Brasil Quilombola apresenta uma série de concepções que nortearão suas ações, tais como a de dignidade humana, qualidade de vida, desenvolvimento sustentável e participação comunitária através da figura do líder representante e/ou das associações representativas.

Remetendo a alguns pontos abordados nos debates que perpassaram o processo de ressemantização, o PBQ, ao esboçar sua definição de "remanescente de quilombos", volta-se à desconstrução do ideário de comunidades isoladas, enfatizando as especificidades territoriais, organizacionais e culturais das comunidades remanescentes de quilombos, enquanto princípio garantidor de direitos. Dentre os objetivos estratégicos estabelecidos pelo Programa, consta o estímulo ao desenvolvimento comunitário e o apoio às associações representativas dessas comunidades.

Diante desses poucos pontos ${ }^{8}$, e considerando o debate acerca da pluralidade semântica do termo "remanescente de quilombos" (ARRUTI, 1997; CHAGAS, 2001), da heterogeneidade de situações que podem ser abarcadas por esta categoria e dos elementos de caráter organizacional, cosmológico, político e representacional apontados por estudiosos que se propuseram refletir criticamente acerca desse novo sujeito, torna-se pertinente o levantamento de algumas questões e o apontamento de

\footnotetext{
${ }^{8}$ Muitos outros poderiam ser abordados, mas não constitui objetivo desse artigo fazer uma análise crítica exaustiva sobre o Programa Brasil Quilombola. Por isso, elegi apenas alguns pontos para servir de base às reflexões contidas neste texto.
} 
algumas considerações sobre a abordagem, ao menos discursivo-legal, que o Estado faz sobre as "comunidades remanescentes de quilombos".

Primeiramente, caberia questionar como seriam possíveis ações pré-definidas atenderem de forma satisfatória aos distintos projetos de desenvolvimento local que cada um desses grupos pode apresentar? De forma latente, evidencia-se a concepção homogênea que marca a apreensão do Estado quanto às configurações dessas coletividades.

É interessante notar que todo o texto adota uma perspectiva cultural-diferencialista, enfatizando o reconhecimento do direito à diferença, não necessariamente o reconhecimento da multiplicidade dos processos de territorialização. Assim, a valorização cultural dos grupos remanescentes de quilombos calca-se no reconhecimento de seus caracteres idiossincráticos, não havendo qualquer apontamento que evidencie que esses coletivos, ainda que classificados sob uma mesma denominação, tenham-se originado a partir de processos históricos específicos, resultando em distintas formas de organização social e econômica, bem como em diferentes formas de construção e apropriação territorial e representação identitária Neste sentido, a ideia de sinal diacrítico toma proporções valorativas que sobressaem aos processos históricos que caracterizam uma relação específica com a terra.

No entanto, para a promoção da igualdade racial e da cidadania, em defesa do direito à diferença, concepções universalistas (e de cunho moral), próprias do pensamento ocidental racionalista moderno que baliza a formação e manutenção do Estado nação, tais como a noção mesma de cidadania, qualidade de vida, dignidade humana e desenvolvimento, são adotadas também como princípios norteadores às ações promovidas pelo Estado brasileiro no âmbito da política quilombola.

Interessante debater mais sobre essa ideia de cidadania, pois a mesma não vem, nos textos jurídicos de regulação e normatização, acompanhada do adjetivo "diferenciada". Assim, podemos considerar que existe um paradoxo na atuação do Estado brasileiro em relação aos grupos étnicos afrodescendentes: ao mesmo tempo em que clama (e reclama) o reconhecimento e valorização dos caracteres diferencialistas que evidenciem seu caráter étnico (e muitas vezes exótico), estabelece como parâmetro de atuação seu enquadramento universalista enquanto cidadão brasileiro. Assim, se, por um lado, 
reconhece-se o direito à diferença, por outro, essa diferença deve ser adequada à ideia de exercício da cidadania, ainda que a aplicação deste conceito implique ações que não necessariamente equivalham às concepções internas desses coletivos de dignidade, respeito, orgulho e pleno exercício de seus deveres, responsabilidades e direitos. Por exemplo, até que ponto a distribuição de cestas básicas, ação promovida no âmbito do PBQ, ao invés da promoção de ações que, de fato, garantam a soberania alimentar desses grupos, atende à ideia que os membros de determinado grupo façam de dignidade? Questões morais são muitas vezes negligenciadas por agências e agentes governamentais que se utilizam de indicadores quantitativos para medirem a eficácia das ações do Estado.

A ideia de que tais ações visam promover a inclusão social "na certeza" de que se está construindo o novo, ou seja, há uma certeza no caminho correto das ações em vista, ainda que pouco se saiba a respeito dessas comunidades. De início, já se fecha a possibilidade de uma análise crítica e qualitativa acerca das proposições governamentais no campo da pluralidade cultural, como se já houvesse alguma expertise no Brasil em lidar com tais situações.

Nesta trajetória, rastreiam-se as imagens de uma equação pautada no desafio e na ousadia destinados à promoção da igualdade racial, a partir de programas e medidas de cunho político e administrativo, visando, coletivamente, a inclusão social, na certeza de que está se construindo o novo e produzindo, assim, coesão em torno de uma agenda nacional que estabeleça acordos para promover a cidadania numa longa e contínua caminhada (BRASIL, 2004).

Outro ponto bastante relevante e que chama a atenção ao longo do texto, é a proeminência dada à figura do líder comunitário e às associações representativas locais. Mas, qual seria a origem desse termo? Até que ponto sua utilização condiz com as estruturas organizacionais dos grupos a que o texto faz referência? Este tipo de ator/sujeito/agente não seria muito mais adequado a outro tipo de organização social? Será que essas lideranças que medeiam as relações de grupos étnicos negros com o Estado correspondem às antigas lideranças locais?

Sobre esse assunto, Chagas (2001) atenta:

No bojo da institucionalização de um nós remanescentes de quilombos ocorrem mudanças que vão depender da maneira com que as comunidades irão lidar com o estatuto do sujeito político, diante de seus próprios modos de interação. Essas exigências de participação, de conversão política, encarnada 
na figura do sujeito político único, muitas vezes entram em contradição com a própria dinâmica que põe em movimento as relações internas às comunidades. Esse é o caso, por exemplo, do sentido e das dificuldades de se concretizar a criação legal de uma Associação, principalmente num cenário de pouca incidência de alfabetização. Diante de uma tal demanda, alguns indivíduos passam a adquirir novo status por um maior desempenho em apropriarem-se das regras da nova situação. A capacidade de um ou outro em saber lidar com o código da escrita, papéis, muitas vezes, pode estabelecer relações de intermediação assimétricas e concentradoras de poder (CHAGAS, 2001, p.225).

Se a política quilombola assenta-se no princípio de respeitar as formas de ser, fazer e existir e busca garantir a sustentabilidade desses grupos através do fomento de suas ações, como seria possível manter as características sociais que marcam a idiossincrasia desses grupos através da imposição da adoção de uma forma muito específica de organização social, política e de representação identitária?

Algumas passagens do texto do Programa Brasil Quilombola desenham (ou tentam desenhar) aproximações entre as comunidades negras contemporâneas e os antigos quilombos, conferindo certa dualidade ao texto que, ao mesmo tempo em que tenta desconstruir a imagem de que essas comunidades seriam resquícios de formações sociais históricas estáticas, busca incessantemente definir as pontes que as conectam com formas específicas de ser, encapsuladas no passado.

É mais plausível afirmar que a ligação com o passado reside na manutenção de práticas de resistência e reprodução do seu modo de vida num determinado local onde prevalece a coletivização dos bens materiais e imateriais (BRASIL, 2004, p.9).

A característica singular que aproxima a dimensão do quilombo no período colonial às mais recentes formas organizativas dos quilombos contemporâneos está presente nas práticas econômicas desenvolvidas, cujos modelos produtivos agrícolas estabelecem uma necessária integração à micro-economia local com vistas à consolidação de um uso comum da terra (IDEM).

Outro ponto, que merece ser refletido, diz respeito ao retrato que parece ter sido feito das comunidades negras rurais de forma cristalizada e estática. A correlação uso comum da terra/comunidade remanescente de quilombos impõe-se soberanamente ao longo do texto, sem relativização acerca de quais seriam as bases desses tipos organizacionais. Seria a apropriação coletiva um recurso acessado dentre muitos ou o único recurso possível a esses grupos? Até que ponto o formato proposto pelo Estado atende aos interesses dessas coletividades? 
É interessante observar como ideias advindas de discussões complexas como sustentabilidade ambiental, social, econômica e política são empregadas no texto sem que antes houvesse qualquer cuidado em apresentar qual a concepção que o Estado tem desses conceitos que nortearão a elaboração, aplicação e a definição dos objetivos da política destinada aos grupos que se autodefinirem "remanescentes de quilombos", como se tais debates, por ocorrerem na esfera pública, fossem articulados de forma consensual entre os diversos agentes envolvidos nos processos de construção de políticas governamentais. Negligencia-se por completo a pluralidade semântica dos termos e conceitos, as questões de ordem política que tornam problemáticas as aplicações de concepções imprecisas em políticas públicas com caráter diferenciado. Esse movimento aponta uma prática que marca a atuação do Estado brasileiro: o esvaziamento da pluralidade em prol da consolidação de uma visão de mundo homogeneizante, incapaz de atentar às sutilezas das diferenças.

De acordo com Pierucci (1990), os debates promovidos no âmbito acadêmico em torno das questões que norteiam as políticas que pretendem atuar no campo da pluralidade cultural e do multiculturalismo, por se assentarem em terreno movediço ${ }^{9}$, apresentamse através de proposições e esquemas teóricos intelectualmente complexos, repletos de sutilezas e nuances que, se não observadas, podem gerar equívocos interpretativos capazes de desvirtuar as análises e esquemas apresentados.

Para o autor, tais equívocos ficam mais suscetíveis de ocorrer quando concepções forjadas no interior do debate acadêmico são transpostas para contextos institucionais de regulação social, tais como um tribunal, pouco favorável às sutilezas e complexidades das racionalizações diferencialistas (PIERUCCI, 1990, p. 25-26).

Souza Lima (2012) atenta aos problemas inerentes à classificação, ou seja, ao processo de inclusão/exclusão através da adoção de critérios aleatórios para a construção dos modelos padronizados que nortearão a promoção de políticas de discriminação positiva,

\footnotetext{
${ }^{9}$ Sobre a complexidade de abordar questões relacionadas à representação do tipo identitária, Hall (2006:1) considera: O próprio conceito com o qual estamos lidando, 'identidade', é demasiadamente complexo, muito pouco desenvolvido e muito pouco compreendido na ciência social contemporânea para ser definitivamente posto à prova.
} 
como por exemplo, as previstas no Programa Brasil Quilombola. De acordo com o autor Souza Lima (2012):

Ao mesmo tempo que enfrentam diretamente certos problemas relativos à desigualdade, os expedientes de discriminação positiva podem levantar outros dilemas, referidos, sobretudo, aos modos pelos quais reconhece a relevância de certos marcadores sociais da diferença em detrimento de outros, ou ainda se convertem sistemas classificatórios complexos em identificações sociais aparentemente objetivas (SOUZA LIMA, 2012, p. 208).

Podemos pensar sobre o esvaziamento ocorrido no processo de deslocamento do campo acadêmico para o campo jurídico, da proposta de ressemantização e dos questionamentos que fundamentaram as reflexões acerca da necessidade de flexibilização da conceituação do termo "remanescente de quilombos", partindo das análises de Santos (2002) sobre o tipo de racionalidade que tem norteado a organização e atuação dos Estados modernos. Para este autor, os Estados sustentam suas ações na razão metonímica, operando a partir de construções binárias e/ou dicotômicas à revelia da heterogeneidade que conforma as sociedades enquanto organizações complexas.

Castro-Gomez (2005) entende que a criação de identidades homogêneas efetua-se por ações diretamente relacionadas à formação do cidadão enquanto "sujeito de direito", sendo fundamental ao projeto moderno de governamentabilidade, o qual se relaciona simbioticamente com a escrita disciplinar. Nas palavras do autor:

\footnotetext{
A formação do cidadão como 'sujeito de direito' somente é possível dentro do contexto e da escrita disciplinar e, neste caso, dentro do espaço de legalidade definido pela constituição. A função jurídico-política das constituições é, precisamente, inventar a cidadania, ou seja, criar um campo de identidades homogêneas que tornem viável o projeto moderno da governamentabilidade (CASTRO-GOMEZ, 2005, p. 89).
}

Apontando para o mesmo sentido e refletindo acerca dos processos de reconhecimento identitários de povos indígenas e quilombolas no Brasil, Arruti (1997) concebe que os rearranjos classificatórios promovidos pelo Estado, quando relacionados a populações submetidas, processam-se em confluência com a redução de suas alteridades, atendendo assim

às necessidades de produção de unidades genéricas de intervenção e controle social, sendo que tais unidades variam segundo aquelas necessidades de controle e domínio (ARRUTI, 1997, p.14).

Mas pensando acerca da construção dos textos jurídicos sobre o "remanescente de quilombos" e a grande distância que os separam da abordagem ressemantizada do 
termo, torna-se interessante questionar sobre qual referencial conceitual, de fato, essa construção assenta-se.

Carvalho (1996), ao analisar a experiência de Rio das Rãs, concebe-a enquanto inserida no texto cultural afro-brasileiro, sendo este texto referenciado no ideário afroamericano.

E mesmo esse texto cultural afro-brasileiro é, apenas, parcialmente autônomo, ou exclusivamente brasileiro; não devemos perder de vista que nossas tradições (sob as quais ainda sabemos pouco) fazem parte de um discurso míticosimbólico ainda maior, que é o grande texto afroamericano (CARVALHO, 1996, p.45 apud Chagas, 2001, p.218).

Ideário esse composto por construções auto imagéticas derivadas da experiência colonial, marcadas por ambivalências que se referenciam em três abordagens epistêmicas que se entrecruzam: (1) a construção do "eu" e do "nós" a partir do olhar do colono; (2) a construção do "eu" e do "nós" a partir da tentativa de ruptura total com o referencial epistêmico do colono, buscando a construção de representações legítimas autoreferenciadas; (3) a construção do "eu" e do "nós" a partir da tentativa de impor ressemantizações de elementos considerados centrais ao referencial epistêmico do colono, na tentativa de reconstruí-los a partir de um olhar nativo.

As análises de Achille Mbembe (2010) sobre o campo de disputa travado entre intelectuais africanos em torno da construção de um discurso africano legítimo, capaz de expressar a África como um todo e o sentido autoconstruído de "ser africano", opondo-se às construções coloniais, fazem-se bastante interessantes para pensarmos o mesmo processo no contexto brasileiro.

Em sua análise, Mbembe (2010) considera que duas correntes de historicismo - a instrumentalista, designada afro-radicalismo, e a nativista, fundamentada no peso da diferença - impediram o avanço de reflexões que contribuíssem com a construção de um quadro autorreferenciado de explicações acerca do passado e do presente em África através de uma referência ao futuro. De acordo com o autor,

a primeira corrente de pensamento - que gostou de se apresentar como "democrática", "radical" e "progressista" - serviu-se de categorias marxistas e nacionalistas para desenvolver um imaginário cultural e político, em que a manipulação da retórica da autonomia, da resistência e da emancipação constitui o único critério para determinar a legitimidade de um discurso africano autêntico. A segunda corrente de pensamento desenvolveu-se a partir de uma ênfase na "condição nativa". Promoveu a ideia de uma identidade africana única assente na pertença à raça negra (MBEMBE, 2010). 
O autor continua apontando como ações não reflexivas, ainda que sob a perspectiva de emancipação, promovem a construção de novas fronteiras, originando novas classificações sociais que seguem respaldadas pelos mesmos princípios de divisão social adotados pelos colonizadores na diferenciação entre colonos e colonizados.

Num lance que replica uma prática etnográfica não-reflexiva, o ex-colonizado atribui um conjunto de características pseudo-históricas a uma entidade geográfica também ela subsumida a uma classificação racial. As características e a classificação são então usadas para identificar ou tornar possível o reconhecimento daqueles que, por possuírem essas características e serem classificados dessa forma, podem ser considerados como pertencentes à colectividade racial e à entidade geográfica assim definida. Sob pretexto de que está a "falar por voz própria", a figura do "nativo" é, pois, reiterada. Estabelecese assim uma fronteira entre o nativo e o Outro não nativo; e, com base nesta fronteira, faz-se a distinção entre o autêntico e o não autêntico (MBEMBE, 2010)

O autor atenta para a forma como o próprio Estado colonial construía essas fronteiras sociais, sempre respaldados por estudos de reconhecimento, cujo principal objetivo consistia em canonizar a diferença e eliminar a pluralidade e a ambivalência do costume. Para o autor, esse processo de reificação da diferença, congrega um paradoxo, pois

Por um lado, assemelha-se a um reconhecimento, mas por outro, constitui um juízo moral, uma vez que, em última análise, o costume só é específico na medida em que indica até que ponto o universo do indígena, na sua naturalidade, não é equiparável ao nosso - em suma, não faz parte do nosso mundo, pelo que não pode servir de base a uma prática de vida em comunidade, numa sociedade civil (MBEMBE, 2010).

Esses processos de classificação reificada, longe de promover o respeito e a valorização da diversidade interna às coletividades, exercem o poder homogeneizante imposto pela lógica que norteia a atuação do Estado colonial, dessubstancializando e esteticizando a diferença, convertendo categorias nativas em "assimilados", "cuja conversão e 'cultura' os torna aptos para a cidadania e para o usufruto dos direitos cívicos" (MBEMBE, 2010).

Para o autor, a partir dessas construções tenta-se localizar a "africanidade num conjunto de características culturais específicas que se espera sejam fornecidas pela investigação etnológica" (MBEMBE, 2010).

Pensando à luz de Mbembe, podemos encontrar referências tanto à perspectiva instrumentalista quanto nativista nos elementos mobilizados na caracterização dos 
"remanescentes de quilombos" nos textos legais. Ideias vinculadas às noções de autonomia, resistência e natividade, são diretamente relacionadas à identidade e identificação desses grupos, enquanto a emancipação (assistida) passa a constituir o objetivo focal das ações de Estado visando à garantia dessas três características.

No entanto, algumas características, tais como o uso do singular em assuntos plurais, constitui-se enquanto uma constante nos textos governamentais (exemplos: cultura tradicional, desenvolvimento), evidenciando a racionalidade dualista através da qual o Estado brasileiro tenta operar suas ações no campo da pluralidade étnica, colaborando no aprofundamento dos entraves semânticos e comunicacionais, próprio do estranhamento causado no contato Estado/minorias étnicas.

\section{Conclusão}

Através do presente artigo, procurei discutir um pouco acerca da categoria jurídica "remanescente de quilombos", apresentando um breve apanhado acerca dos questionamentos levantados, principalmente, ao longo dos anos de 1990 e 2000, e que tinham como objetivo discutir a aplicabilidade do novo termo cunhado pela Constituição Federal brasileira de 1988, bem como seus impactos locais e globais e seus limites.

Tais produções atentavam, sobretudo, à necessidade de adoção de um olhar não homogeneizante como forma de compreender melhor as dimensões tomadas pelo fenômeno Quilombo, na atualidade brasileira, rompendo com mitos e estereótipos que impedem o pleno reconhecimento desses grupos.

A atuação do Estado enquanto agente de classificação identitária, como apontado pelos autores aqui apresentados, gera consequências reais às organizações internas das "comunidades" negras que passam a acessar a política Estatal de reconhecimento de direitos étnicos.

No entanto, o esvaziamento semântico produzido pela abordagem jurídica também gera consequências práticas para além da realidade desses grupos. A adoção acrítica da definição do "remanescente de quilombos" cunhada pelo Estado brasileiro, tanto pelas 
próprias comunidades negras quanto por agentes estatais e estudiosos do tema, pode comprometer imensamente a construção de saberes horizontais, de saberes que contemplem as experiências múltiplas que configuraram o Estado brasileiro tal qual ele se apresenta hoje e colaborem, de fato, com propostas de emancipação social não colonialistas e, tampouco, empobrecidas e fadadas ao fracasso pelo viés da homogeneização ${ }^{10}$.

\section{Referências}

ARRUTI, José Maurício. A Emergência dos "Remanescentes": notas para o diálogo entre indigenas e quilombolas. In: Mana, 1997:7-38.

Direitos Étnicos no Brasil e na Colômbia: notas comparativas sobre hibridização, segmentação e mobilização política de índios e negros. In: Horizontes Antropológicos, Porto Alegre, ano 6, n.14, p. 93-123, nov. 2000.

BRASIL. Programa Brasil Quilombola. Brasília, 2004. Disponível em http://www.seppir.gov.br/central-de-conteudos/publicacoes/pub-comunidadestradicionais/brasilquilombola 2004.pdf/view. Acessado em março de 2017.

CASTRO-GOMEZ, S. Ciências Sociais, violência epistêmica e o problema da "invenção do outro" In: In:LANDER, E. org. A Colonialidade do saber. Eurocentrismo e ciências sociais. Perspectivas Latinoamericanas. Buenos Aires: Clacso, 2005.

CHAGAS, Miriam de Fátima. A política do reconhecimento dos "Remanescentes das Comunidades dos Quilombos. In: Horizontes Antropológicos, Porto Alegre, ano 7, n. 15, p. 209-235, julho de 2001.

HALL, Stuart. A identidade em questão. In: A identidade Cultural na PósModernidade. DP\&A Editora, 1 a edição em 1992, Rio de Janeiro, $11^{\underline{a}}$ edição em 2006,

MBEMBE, Achille. Formas africanas da escrita de si. Tradução Marina Santos. Lisboa, ArtAfrica, $2010 . \quad$ Disponível em http://www.academia.edu/7672216/FORMAS AFRICANAS DA ESCRITA DE SI.

Acessado em agosto de 2016. Não paginado.

\footnotetext{
${ }^{10}$ Como sustentado por Chagas (2000, p. 232-233) “De toda sorte, esse conjunto de questões apresentadas acabam nos indicando que a abrangência do fenômeno das Terras de Quilombo e sua anunciada potencialidade, enquanto signo de inclusão social (LEITE, 1999), dificilmente será levada a cabo sem que a compreensão das distintividades socioculturais e históricas desses grupos sejam explicitados, qualificando seus pleitos à terra de tal modo que se possa conhecer de outro modo, ou seja, reconhecer as diferenças culturais sem substancializá-las ou autenticá-las, mas na sua alteridade crítica que nos faz pensar quem somos."
} 
PIERUCCI, Antônio F. Ciladas da diferença. São Paulo: Editora 34, 1999. In: Tempo Social - Revista de Sociologia da USP. São Paulo, 2 (2), $2^{\circ}$ semestre 1990: 7-33. Disponível em (http://www.scielo.br/pdf/ts/v2n2/0103-2070-ts-02-02-0007.pdf)

REIS, João José. Quilombos e revoltas escravas no Brasil. In: Revista USP, São Paulo (28): 14-39, dezembro/fevereiro 1995-1996.

SOUZA LIMA, Antônio Carlos. Antropologia e Direito: temas antropológicos para estudos jurídicos. Antônio Carlos de Souza Lima (org.). Brasília/Rio de Janeiro/Blumenau: Associação Brasileira de Antropologia/Laced/Nova Letra, 2012.

SOUSA SANTOS, Boaventura de. Para uma sociologia das ausências e uma sociologia das emergências. In: Revista Crítica de Ciências Sociais, 63, p.237-280, Outubro, 2002.

Recebido em 15/05/2017

Aprovado em 27/12/2017 